DOI 10.37882/2223-2982.2020.07.37

\title{
ИССЛЕДОВАНИЕ ПЕРЕВОДА НА РУССКИЙ ЯЗЫК КИТАЙСКИХ КОНСТРУКЦИЙ «ГЛАГОЛ + ОБСТОЯТЕЛЬСТВО РЕЗУЛЬТАТА» V得 C ПОМОЩЬЮ КОРПУСА ЯЗЫКОВЫХ МАТЕРИАЛОВ
}

\section{RESEARCH OF TRANSLATION OF CHINESE CONSTRUCTIONS «VERB + CIRCUMSTANCE OF RESULT»V得 INTO RUSSIAN USING THE CORPUS OF LANGUAGE MATERIALS}

Cui Yufei Chan In

Summary: As a special syntactic structure in Chinese, the construction «verb + circumstance of the result» is widely used, and it is given great attention by scholars studying Chinese grammar. However, since the verb + circumstance construction does not exist in Russian, it is difficult for an online translator to accurately analyze and identify this construction, so incorrect translations are often obtained. The service word v得 Is an important part of the result circumstance in modern Chinese, it has important research significance and applied value. In the case of the modern Chinese language are assembled sentences with 得 constructions in Chinese. These sentences were transliterated into Russian using Google and Yandex online translators, and many incorrect interpretations were found. After analyzing incorrect texts, we selected more accurate ways to adapt Chinese words and expressions to Russian in order to improve the accuracy of translations and improve the system of teaching linguistics itself.

Keywords: verb + circumstance of result; 得; Russian language; online translator

\section{Аспирант, Харбинский научно-технический университет,}

Аспирант, Харбинский научно-технический университет,

Китай, г. Харбин

2464000152@qq.com

Чан Ин

Профессор, Харбинский научно-технический университет, Kuтай, г. Харбин

Аннотация: В качестве особой синтаксической структуры в китайском языке, конструкция «глагол + обстоятельство результата» широко используется, и ей уделяют большое внимание ученые, изучающие китайскую грамматику. Однако, поскольку конструкции «глагол + обстоятельство результата» не существует в русском языке, онлайн-переводчик с трудом точно анализирует и идентифицирует эту конструкцию, поэтому часто получаются неправильные переводы. Служебное слово V得является важной частью обстоятельства результата в современном китайском языке, оно имеет важное исследовательское значение и прикладную ценность. В корпусе современного китайского языка собраны предложения с китайскими конструкциями 得. C помощью онлайн-переводчиков Google и Yandex эти предложения были транслитированы на русский язык, при этом было обнаружено множество неверных интерпретаций. Проанализировав некорректные тексты, были подобраны более точные способы адаптации китайских слов и выражений на русский язык, чтобы повысить точность переводов и совершенствовать саму систему преподавания лингвистики.

Ключевые слова: глагол + обстоятельство результата; 得; русский язык; Онлайн-переводчик

Сюй Тао разъяснил, что структурная связка глагола + обстоятельства результата в китайском языке обычно дополняет и объясняет форму глаголов, и поскольку в русском языке нет такой специальной синтаксической структуры, для перевода требуются другие способы для выражения глагольных форм и действий. К ним относятся словообразование - лексическое, грамматическое (касаемо вида глагола) и даже синтаксическое (в основном относящееся к фразам или предложениям). [3]

В современном китайском языке существует шесть относительно неопределенных глагольных форм, то есть «V了/着/动/得/成/好》. На основании предыдущих исследований в данной статье будут изучаться русские выражения и способы русского перевода «V得».

Эта статья опирается на метод анализа литературы, метод сравнительного анализа и метод комплексно- 
го анализа, используемые для изучения особенностей перевода на русский язык конструкции китайского глагола + обстоятельства результата «V得». Для этого предполагается предпринять следующее: сначала выбрать предложения с различными значениями «V得» B современной китайской лексике, затем воспользоваться переводчиками интернет-систем Google и Yandex, провести сравнительный анализ двух переводов, указать причины неправильного перевода и, наконец, сформулировать русскую интерпретацию выражения «V得». Стоит надеяться, что результаты исследования помогут улучшить аспекты интеллектуального перевода и помочь в понимании китайской речевой культуры.

\section{1. Анализ неверного перево $\Delta а$ «V得》 в онлайн-перево $е$}

В настоящее время инструменты машинного перевода ежедневно обеспечивают более миллиарда переводов для более чем 200 миллионов человек во всем мире. [4] С развитием компьютерной индустрии и наступлением эры глобализации технология онлайн-перевода все более совершенствуется, и его использование все более актуально, но точность перевода все ещё требует доработки. В настоящее время широко используемым в мире инструментом онлайн-перевода является системa Google, а в России используется Яндекс. В процессе перевода китайского языка на русский, из-за сложности первоисточника, иногда одно и то же слово и одна и та же фраза часто может иметь несколько значений или обозначать несколько частей речи. К таким уникальным грамматическим явления китайского языка, можно отнести такие конструкции как глагол + обстоятельство результата, вербализация и т. д. Компьютеру трудно декодировать и кодировать их, поэтому появляются ошибки и случается неверная интерпретация. В этой статье будет два онлайн-перевода, сделанных с помощью систем Google и Яндекс. За основу берется текст, предложения которого содержат конструкцию $\mathrm{c}$ «V得》.

Есть четыре типа частей речи о «得»: (I) Специальные предлоги: Ли Цзиньси рассматривает «得» как фонетический переход предлога «到》 и предлагает термин «специальные предлоги».[5] (2) Суффикс глагола: «得» - исследователь Чжу Дэси предположил подобный термин.[6] Мяо Цзиньань (1990), однако, полагал, что «得» является окончанием слова, которое может объединять и дополнять его последующие компоненты.[7] Ли Линьдин считает, что «得》 - это не независимый синтаксический компонент, а специальное окончание или вспомогательное слово.[8] (3) Постскриптум: Ван Ли называл « 得» постскриптумом.[9] (4) Вспомогательные слова: Фань Сяо считает, что «得» является структурным вспомога- тельным словом, которое является знаком структуры дополнения глагола в синтаксисе [10], Чжан Юйфэн считает, что 《得》 является структурным вспомогательным словом, и указывает, что оно вызвано происходящей вербализацией. [11] Чжао Лисинь считает, что «得» - это структурное вспомогательное слово, и это наиболее часто используемый и широко используемый знак дополнения степени в современном китайском языке. [12]

Эта статья основана на классификации, сделанной исследователями Мэн Цуу, Чжэн Хуайдэ, Мэн Цинхай и Цай Вэньлань, использованной в словаре китайских глаголов. Считается, что «得» является дополнением результата в структуре глагола + обстоятельства результата и делится «得» на два значения:

1. 1.得1: мочь.

2. 这是违反政策的事，可办不得。

3. 教学计划怎么改变不得。

4. 2. 得2: завершение.

5. 豆浆謷得了。

6. 半天的工夫手续就办得了。[13]

\section{1 Анализ неверного перевода глагола «V得1 » в онлайн-переводе}

Предложения, содержащие V得1 и V得2, были отобраны в современном китайском лексиконе, впоследствии был произведен онлайн-перевод данных предложений с использованием служб Google и Yandex. Далее два перевода были проанализированы и сопоставлены. В ходе анализа были обнаружены следующие погрешности перевода:

\section{а. Выбран неподходяший по смыслу глагол}

Как в китайском, так и в русском языках существует лексическая многозначность, то есть одно и то же слово часто имеет много значений, поэтому при выборе слова необходимо выбрать соответствующее его значение в соответствии со смысловой нагрузкой предложения. Однако машинный перевод зачастую не в силах точно проанализировать семантику предложений и выбрать подходящее по смыслу значение слова.

(1)而本国的内部事务别人绝对碰不得。1

G: Другие люди во внутренних делах страны абсолютно неприкасаемы.

Y: И страны во внутренние дела других абсолютно неприкасаемы.

Анализ: Google и Яндекс не смогли определить происхождение, и оба использовали «неприкасаемый» в качестве предиката, что означает «нетронутый и непри-

1 Приведенные ниже примеры предложений взяты из Современного китайского корпуса (CCL) Китайского лингвистического исследовательского центра Пекинского университета 
касаемый». Тем не менее «碰》 имеет много значений в современном китайском языке, здесь «碰》 означает «вмешиваться, интерферировать». Семантика этих двух понятий не является полностью согласованной, и переводы Google и Yandex не могут полно и точно выразить значение конструкции глагола + обстоятельства результата 《碰不得》 в исходном тексте.

Правильный перевод: Другие люди абсолютно не могут вмешиваться во внутренних делах страны.

\section{b. Не идентифицирована связка глагол + обстоятельство результата}

\section{(2) 这仗打得打不得?}

$\mathrm{G}:$ Это можно победить?

Y: Эта битва не может быть выиграна?

Анализ: В исходном предложении есть два глагола + обстоятельства результата, и соответствующие формы положительного 《打得》 и отрицательного 《打不得》. Эта комбинация означает «битва должна вестись или не должна вестись». Перевод Google был неверным. Он не смог идентифицировать глагол + обстоятельство результата и точно передать оригинальную семантику. Перевод не соответствовал грамматическим правилам русских выражений. По сравнению с переводом Google, Яндекс не содержит грамматических ошибок и дословного перевода, его перевод означает «Можно ли выиграть эту битву?». Однако семантический анализ исходного предложения не является точным. Перевод в общем соответствует семантике исходного предложения, но не позволяет целевому читателю точно понять смысл исходного предложения.

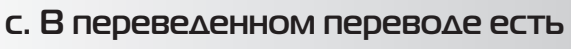 грамматические ошибки}

\section{(3) 拜金主义要不得。 \\ $\mathrm{G}$ : Поклонение золоту не допускается. \\ Y: Этого не может быть.}

Анализ: Оригинальное предложение можно понимать как «не может поклоняться золотому поклонению». Google выбрал несовершенный вид «допускаться», что означает «разрешить», выбрал глагол правильный по смыслу. Структура перевода завершена, правила грамматики верны, и выбор слова верен. Точно выражен первоначальный смысл. Недостатком является то, что идиоматическим русским выражением является «поклонение золотому тельцу» (в значении «меркантилизм»), а не «поклонение золоту». Перевод Яндекса не соответствует грамматическим правилам, не указывает на конкретный предмет, о котором идет речь, вообще никак не переводит основное предложение «поклонение золоту».
Правильный перевод: Меркантилизм не допускается.

\section{2 Анализ неверного перево $\Delta$ a «V得2 » в онлайн-перево $е$}

\section{а. В переведенном переводе есть грамматические ошибки}

(4) 他半斤酒都喝得了。(Здесь произношение «了»«le», а не «liăo»)

$\mathrm{G}:$ Он выпил около половины вина.

Y: Он половину Кэтти вино, пейте его.

Анализ: В первоначальном предложении глагол + обстоятельство результата «喝得了» означает наличие некого умения, а первоначальное предложение означает «он имеет способность / может выпить половину вина». Google в процессе перевода неправильно определил время действия, что привело к расхождению между семантикой перевода и оригинала. Яндекс выбрал несовершенный вид «пить», который не содержит значения «завершение, успех»: субъект и предикат несовместимы до и после предложения, возникли грамматические ошибки, перевод не выполнен, он лишен смысловой нагрузки.

Правильный перевод: Он может выпить 250 грамм алкоголя.

\section{а. Выбран неподходяший глагол}

(5) 这个蛋糕他不一定吃得了。(Здесь произношение «了»- «le», а не «liǎo»)

Y: Этот торт он не обязательно съесть его.

G: Он может не обязательно есть этот торт.

Анализ: V得2 означает «завершение». В русском языке глагол совершенного вида означает что процесс завершен. Следовательно, в русском выражении « $\mathrm{V}$ 得 2», если используется глагол, то он должен быть совершенного вида, иначе первоначальное значение теряет смысл. Google выбрал незаконченный глагол «есть» для выражения «吃», который не выражает значение «завершения», что не соответствует оригинальной семантике.

Правильный перевод: Может быть, он не съест этот торт.

\section{с. Время неверное}

(6) 这个粥做得了。(Здесь произношение «了»- «le», a не «liǎo»)

G: Эту кашу можно сделать.

Y: Эту кашу надо приготовить.

Анализ: Оригинальный текст означает: каша гото 
ва. Хотя Google-переводчиком используется глагол, выражающий законченный процесс «сделать», слово выбрано правильно, но выбор времени неверен, и следует использовать время завершения глагола. В переводе Яндекса используется глагол несовершенного вида «приготовить», что означает «готовый к еде». Выбор слова правильный, но время выбрано неверно. Следует использовать прошедшее время.

Правильный перевод: Эту кашу приготовили.

\section{2. Русское выражение «V得»}

Посредством семантического анализа «V得» и анализа неправильного по смыслу онлайн-перевода дополнительно определяется русское выражение, соответствующее китайскому «V得».

\section{1 Русское выражение «V得 \»}

«得 1» означает «мочь», русское выражение в это время является:

а. нельзя, (не) мочь, (не)возможно и т.д. + глагол

\section{(7) 老虎屁股摸不得。}

Например: нельзя трогать зад тигра

\section{b. (не) мочь быть+ краткая форма страдательного причастии}

\section{(8) 这理由一定要让人拒绝不得。}

Например: эта причина должна не может быть отвергнута.

(9) 这些问题不是一夜之间能改变得了的，这种循环有 时会持续10年。

Например: Эти проблемы не могут быть разрешены за одну ночь. Подобный процесс порой длится 10 лет.

\section{2 Русское выражение «V得2》}

Сюй Тао считает, что глагол + обстоятельство результата в процессе перевода на русский язык, помимо небольшого числа дополнения результата или обозначения степени, которые могут соответствовать словарному запасу в русском языке (например, обозначение степени может использоваться «до» для выражения самой степени), в большинстве случаев должен быть представлен также с помощью словообразования (например, префикса), грамматики (например, использования глагола в корректном виде). Более того, важно то, что некоторые глаголы в больше не являются фиксированной структурой, а только словом (看见 - увидеть), 找一 найти) или сложной фразой (словосочетанием): 写错— написать с ошибками, 跑丟了一双鞋 — потерять ботинки на бегу, 疼得昏死过去 — терять сознание от боли.

《得 2» означает «завершение». Исходя из точки зрения Сюй Тао, при переводе конструкции глагола+ обстоятельства результата «V 得 2» следует использовать грамматические средства для дополнения смысловой и лексической формы глагола. В русском языке грамматическое значение самого глагола совершенного вида всегда подразумевает семантику «завершение», что позволяет сделать вывод:

Русское выражение V得2 : глагол совершенного вида.

(9) 一天工夫怎么办得了!

Например: Как успеть сделать все дела одного дня!

\section{Зак^ючение}

Сравнивая и анализируя тексты онлайн-переводов Google и Yandex можно обнаружить, что данные программные средства в основном имеют следующие недостатки:

1. Неверно выбирают слово. Онлайновый перевод имеет некоторые проблемы при анализе и обработке предложений, что приводит к неправильному выбору слов, особенно к неправильному смысловому выбору соответствующих русских глаголов, такой перевод не позволяет точно и полностью восстановить семантику исходного предложения.

2. В переводе есть грамматические ошибки: отсутствующие компоненты предложения, несоответствующий предмет и предикат и т. д. Из сравнения следует, что Google перевод более точен, чем перевод Яндекса.

В данной статье сделана попытка классификации типичных ошибок машинных переводов. Анализируя результаты онлайн-перевода Google и Yandex, автор пришел к выводу, что, хотя сами ошибки по текстам разнятся, причины подобных ошибок в основном одни и те же. Именно поэтому предложения, содержащие смысловые ошибки перевода должны подлежать классификации и сортировке, чтобы исключить неверную трактовку слов и словосочетаний. Тем не менее, поскольку в рамках проведенного исследования нельзя полностью охватить все особенности построения предложений, а также было рассмотрено лишь небольшое количество примеров неверных переводов, необходимы дальней- 
шие лингвистические изыскания.

Что касается правила русского перевода глагола+ обстоятельства результата «V得», я считаю, что при выполнении русского перевода «V得», мы должны сначала понять его значение, затем выбрать подходящий глагол, и поставить его в правильную форму в соответствии с контекстом предложения. Суть заключается в том, чтобы использовать соответствующие верные русские выражения: если «得» означает «мочь», то надо использовать метод перевода «нельзя / (не) мочь / (не) возможно и т. д.+ глагол», а если
«得》 означет «завершение», то русский глагол следует употреблять в форме совершенного вида прошедшего времени. Таким образом, перевод должен иметь смысловую нагрузку, а грамматика должна соответствовать правилам. Из-за недостаточного количества примеров перевода конструкций глагол+ обстоятельства результата «V得», этот вопрос нуждается в дальнейшем исследовании, изучении и анализе.

ЛИТЕРАТУРА

1. 孟琮，郑怀德，孟庆海等.汉语动词用法词典[Z]. 商务印书馆，2003：12,13.

2. 高京京.近五年动结式研究综述[A].语文学刊，2012 (03) : 41.

3. 徐涛.汉语动补结构的俄译思考[A].中国俄语教学,2012:90.

4. 王悠然.机器翻译难以替代人工翻译[N].中国社会科学报，2015年4月30日第003版:1.

5. 黎锦熙.新著国语文法[M].北京:商务印书馆, 1924 .

6. 朱德熙.《二十世纪现代汉语语法八大家一一朱德熙选集》，沈阳 : 东北师范大学出版社.2001:12.

7. 缪锦安.1990.汉语的语义结构和补语形式[M].上海:上海外语教育出版社.

8. 李临定.带“得”字的补语句[J].中国语文,第5期.1963.

9. 王力.《中国现代语法》[M].北京:商务印书馆.1943.

10. 范 晓.V得句的“得”后成分[J].汉语学习，1992，第6期.

11. 张豫峰.2001.说“得”字句的补语[J].井冈山师范学院学报(哲学社会科学)，第3期.

12. 赵日新.2001.形容词带程度补语结构的分析[J].语言教学与研究，第6期. 